\title{
Spinal dural AV fistula: A nightmare for the anaesthesiologist
}

\author{
Lokvendra Singh Budania ${ }^{1}$, Eeshwar MV ${ }^{2 *}$, Meghna Reddy ${ }^{3}$, Manjunath Prabhu ${ }^{4}$, Yogesh K Gaude ${ }^{1}$, \\ Vamshidhar Chamala Reddy ${ }^{2}$ \\ Associate Professor ${ }^{1}$, Assistant Professor ${ }^{2}$, Junior Resident ${ }^{3}$, Professor ${ }^{4}$, Kasturba Medical College, Manipal, \\ India.
}

\begin{abstract}
Spinal dural arteriovenous fistulas (SDAVFs) are abnormal connections between radicular arteries and venous plexus of the spinal cord. SDAVFs most commonly present with pain and weakness in the lower limbs (which presents as difficulty in climbing stairs, gait disturbances)and sphincter dysfunction that is gradually progressive. We present a 31 year old woman who was diagnosed with stress urinary incontinence and was scheduled for tension free vaginal taping. Spinal anaesthesia was administered and post operatively the patient developed myoclonic jerks and weakness of the lower limbs. On evaluation she was found to have lumbar spinodural AV fistula.
\end{abstract}

Keywords: Spinaldural AV fistula; spinal anaesthesia; stress urinary incontinence

\section{Introduction}

Spinal dural arteriovenous fistulas (SDAVFs) are abnormal connections between radicular arteries and venous plexus of the spinal cord. They are the most commonly encountered spinal vascular malformations but are rare and under diagnosed and affect men who are in their $5^{\text {th }}-6^{\text {th }}$ decade. SDAVFs most commonly present with pain and weakness in the lower limbs (which presents as difficulty in climbing stairs, gait disturbances) and sphincter dysfunction that is gradually progressive. The incidence of SDAVFs is about 5-10 new cases per million persons per year. ${ }^{1-}$ ${ }^{3} \mathrm{We}$ report a 31 year old woman who was diagnosed with stress urinary incontinence and was scheduled for tension free vaginal taping. Spinal anaesthesia was administered and post operatively the patient developed myoclonic jerks and weakness of the lower limbs. On evaluation she was found to have lumbar SDAVF. Diagnosis of this condition preoperatively would have helped prevent further complications.

\section{Case report}

A 31-year-old woman presentedwith inability to micturate voluntarily but ability to pass urine while straining or coughing for the past 2 months. She was diagnosed with stress urinary incontinence (SUI). She gave a past history of spontaneous vaginal delivery 6 months back which was uneventful.

${ }^{*}$ Correspondence: Eeshwar MV

E mail: eeshwar.kmc@gmail.com

https://orcid.org/0000-0003-4138-7814

Received: $18 / 03 / 2019$

Accepted: 02/06/2019

DOI: http://doi.org/10.4038/slja.v27i2.8428
She is otherwise a known hypertensive for the last 1 year on medications. The gynaecologist had planned for a tension free vaginal taping through obturator approach (TVOT). Routine pre-operative investigations were normal. The plan of anaesthesia was spinal anaesthesia. On the day of procedure, under strict aseptic precautions spinal anaesthesia was administered using a $25 \mathrm{G}$ Quincke needle and $10 \mathrm{mg}$ of $0.5 \%$ hyperbaric bupivacaine with $10 \mathrm{mcg}$ of fentanyl was injected intrathecally at L3-L4 intervertebral space. The procedure was performed in lithotomy position and it lasted for about $1 \mathrm{~h}$. The patient was shifted to the post anaesthesia care unit (PACU) and later shifted to the ward.

6 hours into the postoperative period she complained of bilateral lower limb weakness with inability to void urine. Sudden onset of myoclonic jerks were observed and an immediate neurology consultation was obtained. It was found that she had distal hypotonia in both lower limbs and a graded sensory loss up to dermatomes $T_{11}-T_{12}$. She was catheterised in view of difficulty in voiding and a nerve conduction study was performed which was normal. On the postoperative day one, the jerky movements were persistent and the patient was not able to get up from squatting position. Then we probed into her past history, which revealed that she had started experiencing weakness in both lower limbs for the past 6 months after childbirth. The patient concealed this history of weakness in both legs. Magnetic resonance imaging (MRI) was done to rule out epidural haematoma but it revealed serpentine and dilated perimedullary venous plexus seen as flow voids with post contrast enhancement in the lumbar spinal canal suggestive of SDAVF (Figure 1).

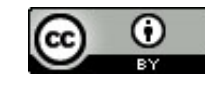




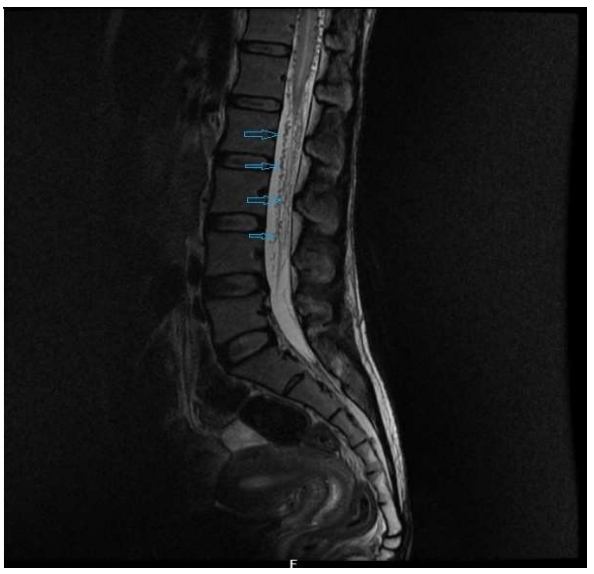

Figure 1

On the third postoperative day we found that the patient was able to stand after squatting with some difficulty and she told us that the weakness was same as what she had experienced preoperatively. Neurosurgical intervention was sought and a digital subtraction angiography with embolization of the AV fistula was advised. Due to the unavailability of the above facilities at our centre, the patient was referred to a centre with said facility.

\section{Discussion}

Spinal anaesthesia is a very common anaesthetic technique performed. It is used for a number of gynaecological procedures including tension free vaginal taping for stress urinary incontinence. SDAVFs are rare neurological disorders which result in various clinical presentations of which involvement of bladder is one. A high degree of clinical suspicion is required to diagnose this condition. Regional anaesthesia is best avoided in these patients as worsening of neurological symptoms has been described.

Owen et al reported a series of three cases of decompensation of undiagnosed SDAVFs after epidural and spinal anaesthesia. Two cases were diagnosed with lumbar canal stenosis and epidural steroid administration had worsened their neurological symptoms after which MRI revealed SDAVF and surgical correction was performed. In one of the cases the patient experienced neurological symptoms after spinal anaesthesia for prostate resection $24 \mathrm{~h}$ into the postoperative period. Outcome in all three cases was favourable. ${ }^{4}$

Hirsch et al had reported paraplegia after epidural for labour analgesia in a patient with undiagnosed SDAVF. Warner et al reported temporary paraplegia after spinal anaesthesia for prostrate resection. ${ }^{5.6}$ Awad et al reported neurological deterioration of a patient who had come with gait disturbances for which diagnostic lumbar puncture was performed. Later MRI and spinal angiography revealed SDAVF and surgical correction was done. ${ }^{7}$

Ong et al reported a patient with cervical SDAVF in whom spinal anaesthesia was safely administered for caesarean section. ${ }^{8}$

Patients with SDAVF already have a high intradural and epidural pressure. Injection of even a small volume of drug in the epidural space could aggravate the neurological symptoms. ${ }^{9}$

In our case, the patient hadn't reported the history of weakness in the lower limbs following child birth to both the gynaecologist and anaesthesiologist. Her symptoms of urinary incontinence were also due to the SDAVF which had led to a misleading diagnosis and administration of spinal anaesthesia.

\section{Conclusion}

A high index of suspicion is needed to diagnose this rare condition due to its varied clinical presentation. Detailed history along with neurological evaluation results in early diagnosis and treatment which can prevent irreversible neurological damage and also help reducing anaesthesia related complications.

\section{References}

1. Thron A. Spinal dural arteriovenous fistulas. Radiologe 2001; 41: 955-60.

2. https://doi.org/10.1007/s001170170031 PMid:11765536

3. Jellma K, Tijssen CC, van Gijn J. Spinal dural arteriovenous: a congestive myelopathy that initially mimica a peripheral nerve disorder. Brain 2006; 129: 3150-64.

https://doi.org/10.1093/brain/awl220 PMid:16921175

4. Jellema K, Canta LR, Tijssen CC et al. Spinal dural arteriovenous fistulas: clinical features in 80 patients. J Neurol Neurosurg Psychiatry 2003; 74: 1438-40. https://doi.org/10.1136/jnnp.74.10.1438 PMid:14570843 PMCid:PMC1757384

5. N.C.Owen, L.T.Smith, L.Massey, A.J.Durnfold, C.E.M.Hillier. Decompensation of undiagnosed spinal dural arteriovenous fistulae after lumbar epidural injection and spinal anaesthesia. Br J Anaesth 2011; 107(1): 109-11. https://doi.org/10.5184/classicalj.107.1.0109

6. Hirsch NP, Child CS, Wijetilleka SA. Paraplegia caused by spinal angioma - possible association woth epidural analgesia. Anesth Analg 1985; 64: 937-40. https://doi.org/10.1213/00000539-198509000-00015

7. Warner DO, Danielson DR, Restall CJ. Temporary paraplegia following spinal anesthesia with a spinal cord arteriovenous malformation. Anesthesiology 1987; 66: 236-7. 
Eeshwar et al. Sri Lankan Journal of Anaesthesiology: 27(2):166-168(2019)

https://doi.org/10.1097/00000542-198702000-00025

PMid:3813088

8. Awad IA, Barnett GH. Neurological deterioration in a patient with a spinal arteriovenous malformation following lumbar puncture. J Neurosurg. 1990; 72(4): 650-3.

https://doi.org/10.3171/jns.1990.72.4.0650

PMid:2181079

9. Ong BY, Littleford J, Segstro R, Petkau D, Sutton I. Spinal anesthesia for caesarean section in a patient with cervical arteriovenous malformation. Can J Anaesth. 1996; 43(10): 1052.

https://doi.org/10.1007/BF03011908

PMid:8896858

10. Hetts SW, Narvid J, Singh T, Meagher S, Corcoran K, Higashida RT, et al. Association between lumbar epidural injection and development of acute paraparesis in patients with spinal dural arteriovenous fistulas. AJNR Am J Neuroradiol. 2007;28(3):581-3.

PMid:17353341 